\title{
Immediate and Long-term Results of Radiofrequency Ablation for Colorectal Liver Metastases
}

\author{
CIPRIAN CIRIMBEI ${ }^{1,2}$, VLAD ROTARU $^{1}$, ELENA CHITORAN $^{1}$, \\ OANA PAVALEANU ${ }^{1}$ and SIMONA ELENA CIRIMBEI ${ }^{1,2}$ \\ ${ }^{1}$ Department of Surgical Oncology, Institute of Oncology "Prof. Dr. Al. Trestioreanu”, Bucharest, Romania; \\ 2 "Carol Davila" University of Medicine and Pharmacy, Bucharest, Romania
}

\begin{abstract}
Background/Aim: Radiofrequency ablation (RFA) of colorectal liver metastases (CRLMs) is a method developed in the last 15 years. It provides an acceptable control of the malignant process with lower risks compared to surgical resection. The aim of the study was to assess immediate and long-term results, including recurrence, survival, morbidity/ mortality rates after RFA. Patients and Methods: Sixty-two cases with CRLMs were treated by RFA during open surgery (89 lesions). Patients were followed-up for a minimum of 36 months, with assessment of recurrences and survival rates at 1, 2 and 3 years, using computed tomography (CT) scan, contrast-enhanced ultrasound and tumor markers (carcinoembryonoc antigen, carbohydrate antigen-19.9). Results: Local relapses, recurrences in other areas and survival rates at 1, 2 and 3 years suggest acceptable values comparative with liver resections in the first 2-3 years and demonstrated long-term limitations, despite the use of adjuvant chemotherapy. Major postoperative negative prognostic factors are tumor multicentricity and tumor's dimensions over $5 \mathrm{~cm}$. Conclusion: RFA of CRLMs is a safe procedure with low rates of local relapses and recurrences, as well as acceptable survival rates, in the first 24-36 months post-procedure. It is recommended for patients with no indications for liver resection or having major resection risks.
\end{abstract}

Liver metastases originating from digestive and extradigestive cancer are the most frequent amongst secondary visceral disseminations, as the liver retains the migrated neoplastic cells while crossing the portal filter. A significant percent (15-30\%) of the colorectal liver metastases (CRLMs)

Correspondence to: Cirimbei Simona Elena MD, Ph.D., Department of Surgical Oncology, Institute of Oncology "Prof. Dr. Al. Trestioreanu" Bucharest, Romania. Tel: +40 722801980, +40 212271000, Fax: +40 213183262, e-mail: simonacirimbei@ yahoo.com

Key Words: Colorectal liver metastases, radiofrequency ablation, recurrence, survival. are synchronous with the primary tumors. They are diagnosed by medical imaging techniques and benefit from targeted therapy. The development of metachronous CRLMs in 30$40 \%$ of the cases is due to tumoral foci spread prior to the ablation of the primary tumor (1). The prognosis of the untreated CRLMs is usually reserved with less than 3-5\% survival rate at 5 years, and directly related to the extension of the metastases into the liver. The survival rates of untreated CRLMs is about 21 months for solitary metastases, followed by 15 months for a limited number of metastases localized in a single hepatic lobe and a maximum survival of 12 months for metastases disseminated in both liver lobes (2).

Treatment of CRLMs is based on chemotherapy and a large variety of surgical procedures (such as liver resections) and local destruction by hyperthermia (radiofrequency ablation (RFA)) or cryotherapy, chemical destruction by alcohol applications, chemotherapeutic destruction by chemoembolization or direct intra-tumoral injection (3), destruction by high-intensity focused ultrasound (HIFU) (4), etc. A therapeutic protocol widely accepted for treatment of liver metastases includes liver resection, as a first option, with the most sustainable results and maximum radicalism. The RFA option is considered when surgical resection is not indicated.

RFA of CRLMs is a therapeutic method developed in the last 10-15 years conferring an acceptable control over the tumoral process. The tumor's destruction is achieved by the conversion of the electromagnetic energy into thermal energy in the tissues, as the electrodes get implanted in the tumor. It has lower risks compared to the surgical resection and is a valid therapeutic alternative. The literature advises that only $15-20 \%$ of the CRLMs have indication for surgical resection (5).

The success of this therapeutic method must be analyzed on the basis of local recurrences (determined by an incomplete destruction), survival index and complication rates (6). An adequate selection of patients and an efficient surgical planning with the use of RFA should lead to low recurrence rates. 


\section{Patients and Methods}

This is a retrospective study, from 2008 to 2012, conducted in Surgery No. 1 Clinic from the Institute of Oncology Bucharest, Romania, that included 62 patients with CRLMs who underwent RFA. The cohort's age ranged from 51 to 78 years. RFA procedures were performed exclusively by open surgery, under intraoperative ultrasound guidance, using a Celon type equipment that generates bi/multipolar RFA. All patients were followed up for a minimum of 36 months, during which patients received 1,2 or 3 cycles of chemotherapy - conventional chemotherapy FOLFOX, FOLFIRI and XELOX (fluorouracil, capecitabine, oxaliplatin, irinotecan) associated with targeted therapy bevacizumab (Avastin ${ }^{\circledR}$ ).

This procedure was taken into account after considering the stage of the neoplastic disease, general health status of the patient, localization, as well as number and size of liver lesions. The main criteria, which led to the selection of our group of patients, were represented by unresectable liver tumors or contraindication for surgery, under 5 liver determinations and/or under 5-8 cm diameter, without contact with the biliary tree, criteria generally accepted in medical practice $(3,6)$ for RFA in the treatment of liver metastases. Exclusion criteria were represented by uncontrollable coagulation with platelets below 50,000 , liver metastasis $>8 \mathrm{~cm}$ in diameter, tumor volume more than $40 \%$ of liver volume, contact with the biliary tree, major surgical-anesthetic risks even for a minimal intervention, coexistence of liver or kidney failure.

There were 89 tumoral lesions treated by RFA with a median value of 1 metastasis per case: 46 cases $(74.2 \%)$ presented a unique lesion, 8 cases $(12.9 \%)$ had 2 liver lesions, 5 cases $(8.97 \%)$ had 3 lesions, and 3 cases $(4.83 \%)$ had 4 lesions. The diameter of the lesions varied between 1.5 and $7 \mathrm{~cm}$, as evaluated by CT scan, with a median value of $3.7 \mathrm{~cm}$. Twenty three lesions had sizes between 1 and $3 \mathrm{~cm} ; 52$ lesions measured 3 to $5 \mathrm{~cm}$, while 14 lesions measured 5 to $7 \mathrm{~cm}$. The majority of the lesions was well-limited and had a non-infiltrative aspect on CT. The destructive process of RFA was monitored by tumor tissue vaporization, tracing gas bubbles emitted around the electrode and the metastatic area swerving from hypo- to hyperechoic, as well as by the disappearance of the tumoral central and peripheral hypervascularization at Doppler ultrasound control (Figure 1).

In 9 cases $(14.5 \%)$, the synchronicity between liver metastases and primary recto-colic tumor required resection of the primary tumor at the same time with RFA of liver metastases. The primary tumor resection was represented by: rectal abdomino-perineal resection (4 cases), right hemicolectomy (3 cases) and sigmoid colectomy ( 2 cases). In 6 cases $(9.67 \%)$ with multiple liver metastases, atypical liver resections (metastasectomies) were performed for peripheral lesions of small sizes $(2-3 \mathrm{~cm})$ simultaneously to RFA in other sites.

The completion of liver lesions evaluation with intraoperative ultrasound exploration allowed us to discover additional liver lesions previously unseen by preoperative imaging in $16.12 \%$ cases (10 patients); this was followed by their resolution.

Patients were followed-up for 3 years and assessed by contrastenhanced ultrasound, CT, magnetic resonance imaging (MRI) and positron emission tomography (PET)-CT scans, as well as by tumor markers (carcinoembryonic antigen (CEA), carbohydrate antigen (CA)-19.9) and specific liver biological tests. The main parameters monitored in the study were represented by the post-procedural complications, local hepatic relapses, recurrences in other hepatic and extrahepatic areas, as well as survival rates at 1,2 and 3 years.
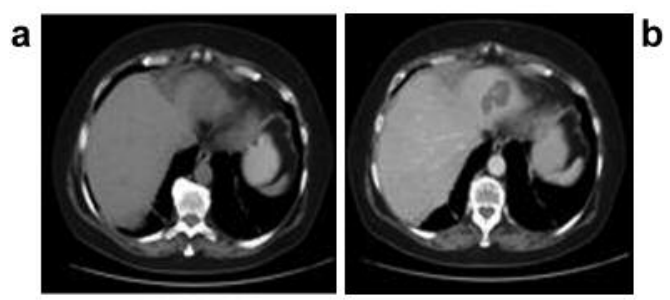

Figure 1. Computed tomography aspect of liver metastases preoperatively ( $a$ ) and 1 month after radiofrequency ablation (RFA) (b). RFA-destroyed tumors appear as hypodense areas without contrast enhancement; a peri-tumoral shadow can be seen sometimes, generated by hyperthermia and inflammatory reaction.

\section{Results}

RFA procedures took place without major complications, such as damage of the neighboring organs like stomach, colon, cholecyst or diaphragm, and without the involvement of major pedicles or intra-hepatic biliary and vascular structures. In 5 cases $(8 \%)$, there was a prolonged hemorrhage at the electrode insertion site but this was resolved by persistent coagulation, including the use of larger caliber electrodes. No complications, such as postoperative hematomas or external biliary fistulae, were recorded; no blood transfusion was needed. The mean intraoperative blood loss was under $100 \mathrm{ml}$.

The postoperative morbidity was $16.12 \%$ (10 cases) represented mostly by minor complications, such as prolonged pyrexia syndrome associated with significant liver cytolysis (5 cases) up to a level of 500 UI for liver enzymes (aspartate aminotransferase (AST), alanine aminotransferase (ALT)), angiocholytic phenomena (3 cases) with leukocytosis up to $16,000 / \mathrm{ml}$ and increased bilirubinemia up to $6 \mathrm{mg}$. These complications were treated with antibiotics for 7 days, followed by a normalizing trend in 5-10 days. In two cases only, we recorded the appearance of liver abcesses in the area of RFA that were treated by percutaneous drainage under CT control (Table I).

There was 1 mortality case $(1.61 \%)$ following an acute myocardial infarction in a 73-year-old patient, 17 days postoperatively.

Recurrences in radiofrequency-ablated areas. The development of recurrences in radiofrequency-ablated areas was diagnosed in $8.06 \%$ of cases ( 5 patients of which one died) after the first year of follow-up, with the percent increasing at $16.12 \%$ (10 patients of which two died) and at $24.19 \%$ (15 patients of which four died) at 2 and 3 years of follow-up. The recurrences in radiofrequency-ablated areas developed at the periphery of the tumor mainly, in the case 
Table I. Characteristics of patients' immediate progress following radiofrequency ablation (RFA) in the first 30 days postoperatively.

Progress characteristics of the study group following RFA in the first 30 days postoperatively (62 cases)

Postoperative morbidity $\quad 16.12 \%$ (10 cases)

Table II. Post-radiofrequency ablation (RFA) progress features for the study group at 1, 2 and 3 years.

\begin{tabular}{|c|c|c|c|c|c|c|c|c|}
\hline \multirow[b]{3}{*}{$\begin{array}{l}\text { Period of } \\
\text { follow-up }\end{array}$} & \multicolumn{8}{|c|}{ Post-RFA progress features for the study group (62 cases) } \\
\hline & \multirow[b]{2}{*}{$\begin{array}{c}\text { Survival } \\
\text { without } \\
\text { signs of } \\
\text { disease }\end{array}$} & \multicolumn{3}{|c|}{ Survival in the presence of disease } & \multicolumn{3}{|c|}{ Deceased } & \multirow{2}{*}{$\begin{array}{c}\text { Surviva } \\
\text { rate }\end{array}$} \\
\hline & & $\begin{array}{l}\text { Local } \\
\text { recurrences } \\
\text { in RFA } \\
\text { areas }\end{array}$ & $\begin{array}{l}\text { Hepatic } \\
\text { recurrences } \\
\text { in other } \\
\text { areas }\end{array}$ & $\begin{array}{c}\text { Extrahepatic } \\
\text { recurrences } \\
\text { without signs of } \\
\text { hepatic recurrences }\end{array}$ & $\begin{array}{l}\text { Local } \\
\text { recurrences } \\
\text { in RFA } \\
\text { areas }\end{array}$ & $\begin{array}{l}\text { Hepatic } \\
\text { recurrences } \\
\text { in other } \\
\text { areas }\end{array}$ & $\begin{array}{c}\text { Extrahepatic } \\
\text { recurrences } \\
\text { without signs of } \\
\text { hepatic recurrences }\end{array}$ & \\
\hline $\begin{array}{l}\text { Post-RFA } \\
\text { progress }\end{array}$ & & & $\begin{array}{l}13 \text { cases } \\
(20.96 \%)\end{array}$ & & & $\begin{array}{l}4 \text { cases } \\
(6.45 \%)\end{array}$ & & \\
\hline $\begin{array}{l}\text { features } \\
\text { at } 1 \text { year }\end{array}$ & $\begin{array}{l}45 \text { cases } \\
(72.58 \%)\end{array}$ & $\begin{array}{l}4 \text { cases } \\
(6.45 \%)\end{array}$ & $\begin{array}{l}6 \text { cases } \\
(9.67 \%)\end{array}$ & $\begin{array}{l}3 \text { cases } \\
(4.83 \%)\end{array}$ & $\begin{array}{l}1 \text { cases } \\
(1.61 \%)\end{array}$ & $\begin{array}{c}1 \text { cases } \\
(1.61 \%)\end{array}$ & $\begin{array}{l}2 \text { cases } \\
(3.22 \%)\end{array}$ & $93.54 \%$ \\
\hline $\begin{array}{l}\text { Post-RFA } \\
\text { progress }\end{array}$ & & & $\begin{array}{l}23 \text { cases } \\
(37.09 \%)\end{array}$ & & & $\begin{array}{c}8 \text { cases } \\
(12.90 \%)\end{array}$ & & \\
\hline $\begin{array}{l}\text { features } \\
\text { at } 2 \text { years }\end{array}$ & $\begin{array}{c}31 \text { cases } \\
(50 \%)\end{array}$ & $\begin{array}{c}8 \text { cases } \\
(12.90 \%)\end{array}$ & $\begin{array}{l}10 \text { cases } \\
(16.12 \%)\end{array}$ & $\begin{array}{l}5 \text { cases } \\
(8.06 \%)\end{array}$ & $\begin{array}{l}2 \text { cases } \\
(3.22 \%)\end{array}$ & $\begin{array}{l}3 \text { cases } \\
(4.83 \%)\end{array}$ & $\begin{array}{l}3 \text { cases } \\
(4.83 \%)\end{array}$ & $87.09 \%$ \\
\hline $\begin{array}{l}\text { Post-RFA } \\
\text { progress }\end{array}$ & & & $\begin{array}{l}32 \text { cases } \\
(51.61 \%)\end{array}$ & & & $\begin{array}{l}19 \text { cases } \\
(30.64 \%)\end{array}$ & & \\
\hline $\begin{array}{l}\text { features } \\
\text { at } 3 \text { years }\end{array}$ & $\begin{array}{c}11 \text { cases } \\
(17.74 \%)\end{array}$ & $\begin{array}{l}11 \text { cases } \\
(17.74 \%)\end{array}$ & $\begin{array}{l}15 \text { cases } \\
(24.19 \%)\end{array}$ & $\begin{array}{l}6 \text { cases } \\
(9.67 \%)\end{array}$ & $\begin{array}{l}4 \text { cases } \\
(6.45 \%)\end{array}$ & $\begin{array}{l}5 \text { cases } \\
(8.06 \%)\end{array}$ & $\begin{array}{c}10 \text { cases } \\
(16.12 \%)\end{array}$ & $69.35 \%$ \\
\hline
\end{tabular}

of metastases, with initial sizes of over $4 \mathrm{~cm}$ in diameter; over $70 \%$ (11 cases) had a diameter of more than $5 \mathrm{~cm}$. The diagnosis of the reactivation of the tumors was signaled in a variable interval of 5-28 months post-procedure, representing a continuity of the disease, even under chemotherapy. Diagnosis was based on the increase of tumor markers (CEA, CA-19.9) level and CT/MRI evaluation with contrast enhancement, thus demonstrating non-homogenous areas post-RFA application, with tumor revascularization. In 3 cases of relapse developed post-procedurally, a repeated RFA was performed, followed by an 8- to 12-month disease-free period. We would like to highlight that more than $70 \%$ of the recurrences in radiofrequency-ablated areas developed in the first 24 months post-procedurally (Table II).

Recurrences in other liver areas. Post-procedural, patients progress is frequently marked by the development of metastatic recurrences in other liver areas and this was noticed the first year of follow-up in $11.29 \%$ of cases (7 patients of which one died), after the second year of follow-up in $20.96 \%$ of cases (13 patients of which three died) and at the end of the third year of follow-up in $32.25 \%$ of cases (20 patients of which five died). Metastatic recurrences had variable dimensions, number and topography; they were not correlated, however, to the dimensions of the initial metastases but rather to the existence of an initial multicentricity. In 10 cases $(66.66 \%)$, there was an initial multiple liver lesion and an initial single metastasis, in 5 cases $(33.33 \%)$ only. The detection of the recurrences was between 4 and 27 months post-procedurally, while all the patients had received chemotherapy. Therefore, we can conclude that both local and distant relapses developed in the first 24 months post-procedurally regardless of chemotherapy (69\% of cases). Approximately, $30 \%$ of the metastatic relapse cases were detected next to the initial radiofrequency-ablated 


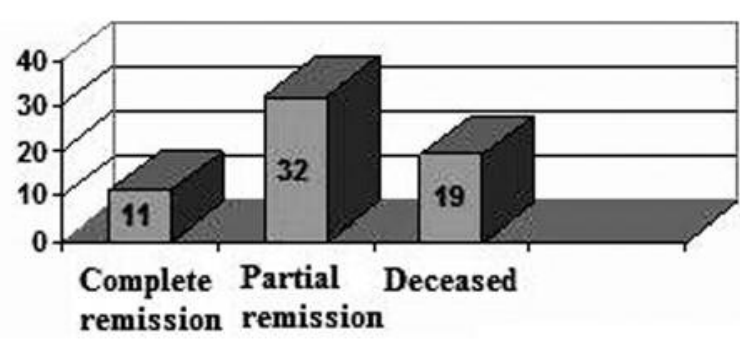

$\square$ Number of cases

Figure 2. The post-interventional response at 36 months of follow-up.

areas, thus, difficult to discriminate between local and metastatic relapse.

Extrahepatic recurrences without signs of hepatic recurrences. Regarding extra-hepatic recurrences, for the group with CT and PET-CT imaging follow-up, we recorded their development in $25.8 \%$ of cases (16 patients of which ten died); pulmonary metastases have been the most frequent but also splenic and multivisceral (lymphadenopathies with bowel invasion, recurrences at anastomotic level, peritoneal carcinomatosis and so forth).

During the follow-up period of 36 months, 19 deaths (30.64\% of cases) were recorded due to occlusive syndromes, liver failure, neoplastic consumption or cardiovascular accidents in patients with progression of liver and/or extrahepatic disease (Figure 2).

One-, two- and three-year survival rates were of $93.54 \%$, $87.09 \%$ and $69.35 \%$, respectively, but, in only 11 patients $(17.74 \%)$, we recorded an apparently complete healing without hepatic or extrahepatic disease signs at 3 years following RFA. The other 32 cases $(51.61 \%)$ that were alive after 3 years presented signs of disease in the form of local relapses at RFA areas (11 cases (17.74\%)), metastatic recurrences in other liver areas (15 cases $(24.19 \%))$ or extrahepatic recurrences (6 cases $(9.67 \%)$ ) (Figure 3).

\section{Discussion}

The aim of this study was to evaluate the potential of RFA of liver metastases originating from colorectal cancer in a period when minimally invasive techniques gain more ground over classical surgery. Nowadays, there is much debate on the indications, advantages and value of RFA; there is a lack of consensus and different approaches, varying from chemotherapy only to invasive procedures like major liver resections (7), with a large spectrum of minimally invasive procedures (chemoembolization, RFA, cryoablation, LASER-therapy, etc.).

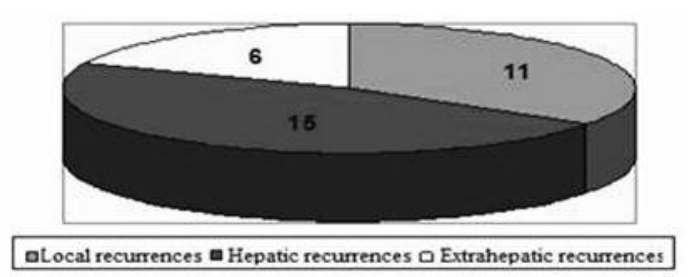

Figure 3. Survival in the presence of disease with partial remission at 36 months post-procedurally.

The destruction by radiofrequency becomes a treatment link in the modern multimodal therapeutic protocol of liver metastases, constantly associated with chemotherapy or other surgical or non-surgical methods (8). The value of the method consists in the possibility of achieving complete tumoral destruction in the case of liver metastatic lesions less than 4-5 $\mathrm{cm}$ and debulking for more voluminous ones (9); the method does not replace hepatic resection that theoretically remains the gold standard for this type of lesions.

The preference towards hepatic resection or RFA is still controversial. The majority of the studies conclude that RFA is associated with higher liver recurrence rates short after the procedure but with a long-term survival comparable to the resection, at least at 24-36 months.

RFA originates from a similar concept to surgery (extirpating tumors) and, as it targets a specific tumoral volume, can be regarded as a minimal invasive procedure. The intra-procedural control is offered by the intraoperative "real-time" ultrasound that ensures a quantitative and qualitative control over the tumoral ablation together with the $1 \mathrm{~cm}$ safety border. There is also a simultaneous diagnosis of other preoperatively non-described lesions (10). This solution is obviously less traumatic than liver resection, as the postoperative recovery is faster. Also, interestingly, the gastrointestinal tract and spinal cord are not affected as compared with conventional chemotherapy.

Hager et al. (11) conducted a non-randomized trial on 80 patients in which they compared the efficacy of RFA for liver metastases from colorectal cancer (CRC) with standard chemotherapy from previous cases. The 3-year survival rate for patients with liver metastases from CRC treated with RFA+chemotherapy was twice the survival from the previous cases treated with chemotherapy only. The 2-year survival rate for patients treated with RFA was $51 \%$ in comparison with $36 \%$ for the control group. The mean survival for patients who benefited from RFA+chemotherapy was higher than previous control cases that benefited from chemotherapy only (24.1 months as compared with 8 to 11 months).

On the other side, Oshowo et al. (12) conducted a smaller controlled prospective study where they compared 2 groups of patients with liver metastases from CRC; the first group had 
surgical interventions $(n=20)$ and the second one RFA $(n=25)$. The mean survival after RFA was 37 months (range=9-67) with a 3-year survival rate of $52.6 \%$, while the mean survival after liver resection was 41 months (range $=0-97$ ) with a 3-year survival rate of $55.4 \%$. The investigators concluded that the preliminary survival rate for the RFA-treated patients was comparable to that of patients treated by liver resection.

The prospective study conducted by Solbiati et al. (13) also evaluated the efficiency of RFA for liver metastases secondary to CRC. A number of 117 patients with 179 metastatic tumors were treated with RFA, with the dimension of the metastases being between 0.6 and $9.6 \mathrm{~cm}$. The aims of their study included survival rate, tumor recurrence and time interval until the development of new metastases, survival time and recurrence time for each individual lesion. The mean survival was 36 months (range $=28-52$ ); the survival rates at one, two and three years were $93 \%, 69$, and $46 \%$, respectively. In $66 \%$ of the cases, new metastases were discovered after a mean follow-up of 12 months. The authors concluded that RFA is an efficient method for the treatment of liver metastases from CRC.

The complete control of the tumoral destruction by radiofrequency was proved to be directly proportional to the initial metastatic size with an estimate of complete ablation rate that explains the higher relapse frequency for metastases larger than $4-5 \mathrm{~cm}$.

Hildebrand et al. also mention similar conclusions (14) reported on a group of 88 patients consecutively treated by RFA for unresectable tumors $(8 \%)$ or metastases $(92 \%)$. One-, two- and three-year survival rates were $90 \%, 65 \%$ and $40 \%$, respectively, with a mean survival rate of 27 months. In a 21.2-month follow-up post-RFA, 15 patients (17\%) developed a local tumor progression. The latter was signaled to be higher in percutaneously treated patients $(16.3 \%)$ than those treated by surgery (10.4\%). Additional hepatic lesions were identified by intraoperative ultrasound in 27 out of the 77 cases $(35 \%)$. The authors concluded that intraoperative or percutaneous RFA was an efficient treatment for both primary and metastatic liver cancer patients.

A more recent prospective clinical study of Abitabile et al. (15) on a group of 47 patients with hepatic metastases from CRC treated by RFA indicated the fact that the resection was not feasible in $80 \%$ of the cases. The mean postinterventional follow-up was 33 months. The RFA-associated morbidity was $7 \%$. The one-, two- and three-year survival rates were $88 \%, 80 \%$ and $57 \%$, respectively. The local recurrence rate was $8.8 \%$ for the entire group and $1.6 \%$ for the metastatic lesions with a diameter of less than $3 \mathrm{~cm}$. According to the researchers, RFA should be indicated for tumors under $3 \mathrm{~cm}$ and by an open surgical approach.

From the perspective of our results and the literature review, we can highlight the following: the survival rates following liver resections and RFA are statistically comparable in the first 1 to 2 years post-procedurally, although RFA offers lower morbidity and mortality; the postprocedural recurrence at distance is low in the case of initial small (less than $3 \mathrm{~cm}$ ) liver metastases; however, it increases proportionally with the metastatic size; the local relapse rates in the ablated areas are low in the case of small (less than 3 $\mathrm{cm}$ ) liver metastases; however, they increase proportionally with the metastatic size. Over $75 \%$ of the reactivated lesions had an initial diameter of over $5 \mathrm{~cm}$. Over $70 \%$ of the recurrences developed in the first 24 months after the procedure; the metastatic recurrences in other liver areas are not correlated to the initial metastatic dimensions but to the initial multicentricity.

\section{Conclusion}

RFA of liver metastases is a relatively safe procedure with relatively low rates of local relapse and recurrence in other areas and acceptable survival rates at 24-36 months postprocedurally. It is indicated in those cases not suitable for liver resection. The method can be used in lesions over $5-7 \mathrm{~cm}$ and has the role of liver tumoral mass debulking.

The procedure can be regarded as a minimal invasive technique with short hospitalization period and minimal costs. It represents a therapeutic alternative for the local control of liver metastases originating from colorectal cancer. However, surgical excision remains the standard treatment for the complete control of this disease.

\section{References}

1 Leporrier J, Maurel J, Chiche L, Bara S, Segol P and Launoy G: A population-based study of the incidence, management and prognosis of hepatic metastases from colorectal cancer. Br J Surg 93(4): 465-474, 2006.

2 Wagner JS, Adson MA, van Heerden JA, Adson MH and Ilstrup DM: The natural history of hepatic metastases from colorectal cancer. A comparison with resective treatment. Ann Surg 199(5): 502-508, 1984.

3 Tsoulfas G, Pramateftakis MG and Kanellos I: Surgical treatment of hepatic metastases from colorectal cancer. World J Gastrointest Oncol 3(1): 1-9, 2011.

4 Popescu I, Sîrbu-Boeţi MP, Tomulescu V, Ciurea S, Boroş M, Hrehoreţ D and Jemna C: Terapia tumorilor hepatice maligne cu microunde şi unde de radiofrecvenţă. Chirurgia 100(2): 111-120, 2007.

5 Wood TF, Rose DM, Chung M, Allegra DP, Foshag LJ and Bilchik AJ: Radiofrequency ablation of 231 unresectable hepatic tumors: indications, limitations, and complications. Ann Surg Oncol 7(8): 593-600, 2000.

6 Tanis E, Nordlinger B, Mauer M, Sorbye H, van Coevorden F, Gruenberger T, Schlag PM, Punt CJ, Ledermann J and Ruers TJ: Local recurrence rates after radiofrequency ablation or resection of colorectal liver metastases. Analysis of the European Organisation for Research and Treatment of Cancer \#40004 and \#40983. Eur J Cancer 50(5): 912-919, 2014. 
7 Sandhu L, Fox A, Nhan C, Barnett H, McLeod RS, Gallinger S and Moulton CA: Assessing the management of hepatic colorectal cancer metastases: Is treatment consistent in Ontario? HPB (Oxford) 14(6): 409-413, 2012.

8 McNally SJ and Parks RW: Surgery for colorectal liver metastases. Dig Surg 30(4-6): 337-347, 2013.

9 Pawlik TM, Abdalla EK, Ellis LM, Vauthey JN and Curley SA: Debunking dogma: Surgery for four or more colorectal liver metastases is justified. J Gastrointest Surg 10: 240-248, 2006.

10 Takeuchi N, Ramirez JM, Mortensen NJM, Cobb R and Whittlestone T: Intraoperative ultrasonography in the diagnosis of hepatic metastases during surgery for colorectal cancer. Int J. Colorect Dis 11(2): 92-95, 1996.

11 Hager ED, Dziambor H, Höhmann D, Gallenbeck D, Stephan M and Popa C: Deep hyperthermia with radiofrequencies in patients with liver metastases from colorectal cancer. Anticancer Res 19(4C): 3403-3408, 1999.

12 Oshowo A, Gillams A, Harrison E, Lees WR and Taylor I: Comparison of resection and radiofrequency ablation for treatment of solitary colorectal liver metastases. Br J Surg 90(10): 1240-1243, 2003.
13 Solbiati L, Livraghi T, Goldberg SN, Ierace T, Meloni F, Dellanoce M, Cova L, Halpern EF and Gazelle GS: Percutaneous radiofrequency ablation of hepatic metastases from colorectal cancer: Long-term results in 117 patients. Radiology 221(1): 159-166, 2001.

14 Hildebrand P, Kleemann M, Roblick UJ, Mirow L, Birth M, Leibecke $\mathrm{T}$ and Bruch HP: Radiofrequency ablation of unresectable primary and secondary liver tumors: Results in 88 patients. Langenbecks Arch Surg 391(2): 118-123, 2006.

15 Abitabile P, Hartl U, Lange $J$ and Maurer CA: Radiofrequency ablation permits an effective treatment for colorectal liver metastasis. Eur J Surg Oncol 33(1): 67-71, 2007.

Received April 13, 2017

Revised May 1, 2017

Accepted May 2, 2017 